\title{
Supplemental Table.
}

Table S2: Relative content (\%) of the Individual amino acids [AA] measured in the diatom Cylindrotheca fusiformis. A total of 12 AA were identified and quantified. The analysis of the specific AA groups showed that the Essential (EA) represented $40 \%$ and Non-essential (NEA) the remaining $\sim 60 \%$.

\begin{tabular}{|c|c|c|c|c|c|c|c|c|c|c|c|c|c|c|c|c|c|c|}
\hline & Temp. ${ }^{\circ} \mathrm{C}$ & 14 & 14 & 14 & 14 & 14 & 14 & 14 & 14 & 14 & 19 & 19 & 19 & 19 & 19 & 19 & 19 & 19 \\
\hline & $\mathrm{CO}_{2}$ ( $\mu$ atm) & 180 & 180 & 180 & 380 & 380 & 380 & 750 & 750 & 750 & 180 & 180 & 380 & 380 & 380 & 750 & 750 & 750 \\
\hline \multicolumn{19}{|l|}{ Type } \\
\hline E & Val & 7.57 & 8.00 & 5.13 & 7.80 & 8.02 & 7.72 & 7.08 & 7.69 & 5.58 & 6.70 & 6.07 & 7.06 & 7.49 & 6.70 & 6.66 & 7.67 & 6.85 \\
\hline$E$ & Ile & 5.28 & 5.27 & 3.28 & 6.83 & 5.33 & 6.02 & 5.14 & 5.32 & 3.81 & 5.12 & 4.97 & 5.38 & 4.91 & 4.98 & 4.81 & 6.09 & 5.65 \\
\hline E & Leu & 10.75 & 12.06 & 10.67 & 12.75 & 12.26 & 12.39 & 10.57 & 11.27 & 11.88 & 11.00 & 11.89 & 11.60 & 12.25 & 10.85 & 12.29 & 11.80 & 12.46 \\
\hline$E$ & Lys & 2.90 & 2.70 & 4.98 & 6.21 & 4.16 & 3.87 & 5.64 & 2.62 & 4.77 & 6.38 & 8.09 & 6.80 & 4.37 & 5.86 & 7.55 & 4.94 & 7.46 \\
\hline E & Met & 1.90 & 1.23 & 2.56 & 2.02 & 1.95 & 1.38 & 1.43 & 1.01 & 1.61 & 2.06 & 2.54 & 2.16 & 2.51 & 2.44 & 2.31 & 2.86 & 2.21 \\
\hline E & Phe & 5.27 & 6.55 & 5.34 & 7.66 & 5.76 & 6.56 & 5.71 & 5.39 & 6.87 & 5.37 & 6.71 & 6.32 & 6.06 & 5.86 & 6.42 & 5.94 & 6.77 \\
\hline NE & Pro & 7.10 & 6.61 & 6.04 & 6.70 & 6.62 & 6.61 & 6.70 & 6.35 & 6.38 & 5.82 & 5.32 & 5.83 & 5.64 & 5.18 & 6.42 & 6.05 & 5.20 \\
\hline NE & Tyr & 1.59 & 2.24 & 2.30 & 2.83 & 1.52 & 2.67 & 2.14 & 1.71 & 2.87 & 2.53 & 3.05 & 2.28 & 2.00 & 2.68 & 2.99 & 2.71 & 3.25 \\
\hline NE & Ala & 16.03 & 14.16 & 14.14 & 12.81 & 14.83 & 13.52 & 12.82 & 14.75 & 15.43 & 12.87 & 11.50 & 14.35 & 13.45 & 12.19 & 13.31 & 13.71 & 11.04 \\
\hline NE & Asx & 13.75 & 13.57 & 14.34 & 12.70 & 14.09 & 12.75 & 15.12 & 13.18 & 14.97 & 13.02 & 12.61 & 11.67 & 13.45 & 13.62 & 12.79 & 12.89 & 12.08 \\
\hline NE & Glx & 12.33 & 12.41 & 18.01 & 9.99 & 11.17 & 13.26 & 16.03 & 16.36 & 10.59 & 16.65 & 16.45 & 12.48 & 14.51 & 18.84 & 10.02 & 11.36 & 15.98 \\
\hline NE & Gly & 15.54 & 15.21 & 13.21 & 11.71 & 14.27 & 13.25 & 11.62 & 14.35 & 15.24 & 12.48 & 10.81 & 14.08 & 13.35 & 10.82 & 14.43 & 14.00 & 11.04 \\
\hline
\end{tabular}

